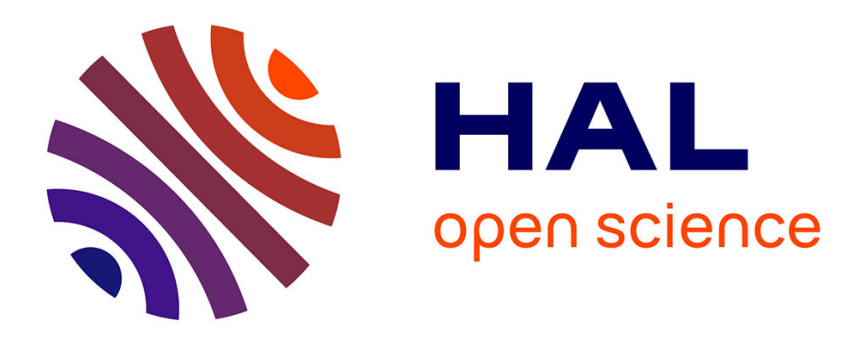

\title{
THERMODYNAMICS AND STRUCTURE OF UNDERCOOLED LIQUID METALS
}

\author{
C. Regnaut, J. Bretonnet
}

\section{To cite this version:}

C. Regnaut, J. Bretonnet. THERMODYNAMICS AND STRUCTURE OF UNDERCOOLED LIQUID METALS. Journal de Physique Colloques, 1985, 46 (C8), pp.C8-669-C8-673. 10.1051/jphyscol:19858109 . jpa-00225151

\section{HAL Id: jpa-00225151 https://hal.science/jpa-00225151}

Submitted on 1 Jan 1985

HAL is a multi-disciplinary open access archive for the deposit and dissemination of scientific research documents, whether they are published or not. The documents may come from teaching and research institutions in France or abroad, or from public or private research centers.
L'archive ouverte pluridisciplinaire HAL, est destinée au dépôt et à la diffusion de documents scientifiques de niveau recherche, publiés ou non, émanant des établissements d'enseignement et de recherche français ou étrangers, des laboratoires publics ou privés. 
JOURNAL DE PHYSIQUE

Colloque $\mathrm{C} 8$, supplément au $\mathrm{n}^{\circ} 12$, Tome 46, décembre 1985

page $\mathrm{C} 8-669$

\title{
THERMODYNAMICS AND STRUCTURE OF UNDERCOOLED LIQUID METALS
}

\author{
C. Regnaut and J.L. Bretonnet ${ }^{+}$ \\ LP15 du CNRS, Physique des Liquides et Ezectrochimie, Tour 22, 4, place \\ Jussieu, 75230 Paris Cedex 05, France \\ and \\ UER de Saint-Quentin, Université de Picardie, France \\ ${ }^{+}$Laboratoire de Physique des Liquides Métaliziques, Université de Metz, \\ 57045 Metz, Fronce
}

Résumé - On étudie 1'évolution de métaux purs surfondus depuis la température de fusion $T_{M}$ jusqu'à $0.5 T_{M}$. Par la thẻorie du pseudopotentiel et 1 'ORPA, on prêvoit une accentuation des particularités structurales. Le rôle déterminant des interactions à moyenne et longue portée est mis en avant aussi bien dans 1 'état surfondu que dans 1 'état amorphe de $\mathrm{Ga}, \mathrm{Sn}, \mathrm{Bi}$.

Abstract - We study the structural evolution of undercooled pure metals from the melting temperature $\mathrm{T}_{\mathrm{M}}$ to $0.5 \mathrm{~T}_{\mathrm{M}}$. By means of the pseudopotential theory and ORPA we predict an increase of the structural trends. The prime importance of the intermediate and long ranged interactions is underlined to understand the undercooled state as well as amorphous state of $\mathrm{Ga}, \mathrm{Sn}, \mathrm{Bi}$.

\section{I - INTRODUCTION}

It is striking that the pure metals which can be obtained at deep level of undercooling: $\mathrm{Ga}, \mathrm{Hg}, \mathrm{Sn}, \mathrm{Bi} / 1,2 /$ have a non hard-sphere-like liquid structure, since their structure factor $S(q)$ and pair correlation function $g(r)$ exhibit special distorsion. A good link between the effective interionic pair potential $V(r)$ and the structure can be realized by thermodynamic perturbation theories such as the ORPA /3/ which is suitable for liquid metals /4/. Recently, Hafner and Kahl /5/ have fairly classified a 11 the structural trends observed in liquid metals in terms of the systematic variations of $V(r)$ with electron density and local pseudopotential. However, a more quantitative study of the thermadynamics and structure of the previous metais needs the use of non local pseudopotential $/ 4,6 /$. Thus, specific effects due to the long ranged part of $V(r)$ can be pointed out on the temperature derivative of the resistivity (TDR) $17 \%$.

In this work, we intend to examine if the pseudopotential and the ORPA formalism can works well below the melting temperature $\mathrm{T}_{\mathrm{M}}$. The ultimate temperatures which have been reached in the undercooled droplets of metal, just before their spontaneous crystaliization, are close to $0.5 \mathrm{~T}_{\mathrm{M}} / 1,2 /$. Several theories have been presented to define the structural and thermodynamical behaviour near this experimental limit $/ 8, \%$. Few measurements have been done, and they principally concern the structure of $\mathrm{Ga} / 1 /$ and the heat capacity $C_{p}$ at constant pressure $12 \%$. So we concentrate ourselves on these properties and on the TDR since non linear variations for $T<T_{M}$ have been predicted by Pokorny and Aström $/ 10 \%$, as a consequence of their measurements for $T>T_{M}$. As a matter of comparison with $\mathrm{Ga}, \mathrm{Sn}, \mathrm{Bi}$ we also consider hypothetical states of undercooled $\mathrm{A}$ ? .

\section{II - SHORT DESCRIPTION OF THE MODELS}

Before considering the undercooled liquid, we have defined a representation of the pseudopotential which allows a good description of the normal liquid in the range $\mathrm{T}_{\mathrm{M}}$ $1.5 \mathrm{~T}_{M}$. We follow the procedure and references given in $/ 6 \%$. The bare-ion pseudopotential $v_{p s}$ is represented by the non show-local model of shaw. We define the exchange correlation terms as Vashishta and Singwi. One important point is that we do not include effective masses in the case of $\mathrm{Sn}$ and $\mathrm{Bi}$ since such masses give an unrealis- 
tic pair potential for these two metals. The calculation of the structure and thermodynamics is done from the ORPA. The reference system is the fluid of hard-sphere (HS), which diameter $\sigma$ is defined from the repulsive core of $V(r)$. Then the correlation function $C_{a}(r)$ induced by the oscillatory part of the potentia $i, V_{a}(r)$, is calculated in terms of an optimized potential $V_{a}^{*}(r)$. This means that the usuai RPA expansion $C_{a}(r)=-V_{a}(r) / k_{B} T$ for $r>\sigma$ is optimized for $r<\sigma$ so that the pair correlation function $g(r)$ is effectively zero for distances $r<\sigma$. Therefore the modified structure factor is expressed from the hard-sphere one $S_{\sigma}(q)$ and $V_{a}^{\prime}(q)$.

$$
S(q)=S_{\sigma}(q)\left[1-v_{a}^{*}(q) S_{\sigma}(q) / k_{B} T\right]^{-1}
$$

For simplicity, we do not discuss the supplementary soft core correction to (1) which permits the adjustment of $\sigma$. However, this correction is considered in our calculation.

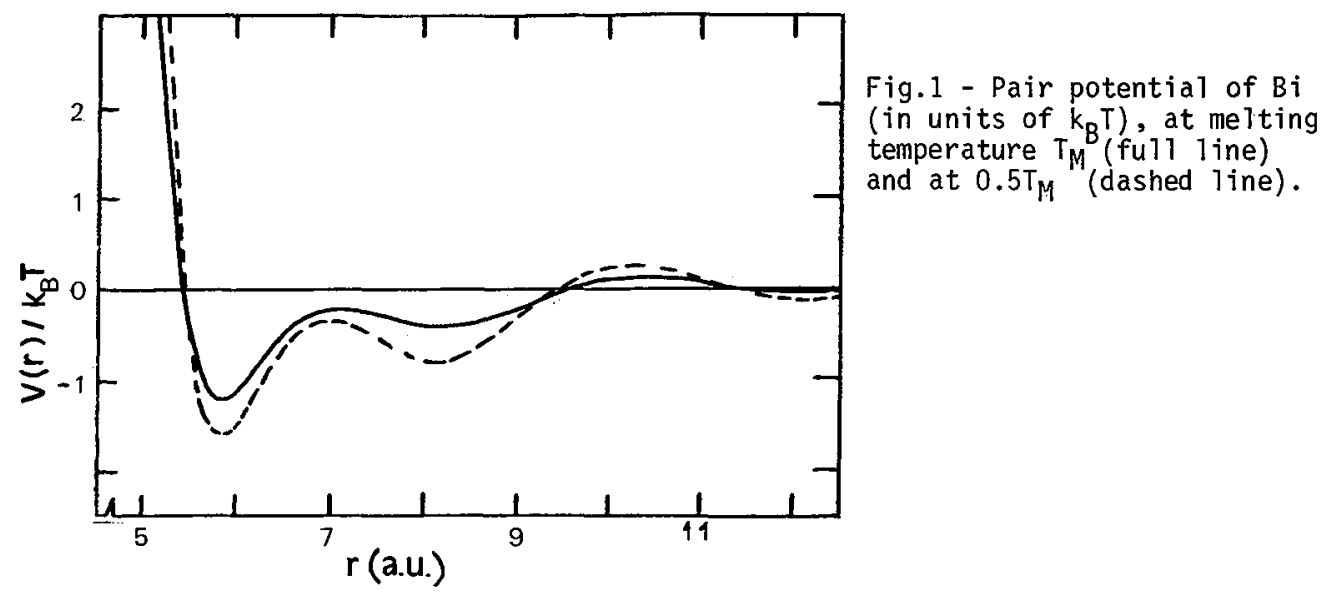

The variation of the liquid density with temperature is assumed to follow the linear parametrization of Crawley $/ 1 /$. The change of $S(q)$ depends on temperature, through (1) and on the density. The density dependence is explicit in the packing fraction of the $H S$, but it is implicit in $V(r)$ through the modifications of the screening length, the Friedel wawelength and the core parameters of vps $/ 5 /$. Here, this variations are fully taken into account. In fig.1, we have represented $V(r) / k_{B} T$ at $T=T_{M}$ and $0.5 T_{M}$. We see that the undercooling with favor the emergence of the long ranged correlations relatively more than those of the first attractive well region.

Once $S(q)$ and its real space equivalent $g(r)$ are obtained, the computation of the excess free energy, of the heat capacity and of the resistivity (through the Ziman formula) are straight forward.

\section{III - RESULTS AND DISCUSSION}

The evolution of the structures from $T_{M}$ to $0.5 T_{M}$ are presented in fig.2. Considering first Ga, we obtain a moderate quantitative agreement with the experiment at $T_{M}$ and $0.5 \mathrm{~T}_{M}$. This is not surprising since we have performed ab initio calculation, $i$.e. without adjustement of the core radius $R_{j}$ of $v_{p s}$, to better fit the data. The important result is that the model reproduces the change of $S(q)$ with temperature, $i . e$. the increase of the principal peak and of its shoulder as well as the evolution of the profile of $g(r)$. In particular, all the special wiggles on $g(r)$, al though too much pronounced in the model are placed exactly where similar wiggles are found in the pure amorphous Ga or in the corresponding quasicrystalline model of $\beta-\mathrm{Ga}$. $\beta$ - Ga is the metastable structure in which the deep undercoofed liquid prefers to crystalize /12/.

In the case of $A]$, no tendancy to any asymetry in $S(q)$ appears at low temperature (fig.2b). This would have been expected from the increasing influence of the Friedel oscillations alone. In fact, what we observe is in ful1 agreement with the trends predicted by Hafner and Kahi in terms of the variation of $r_{C} / r_{S}$ (the ratio of the 
ionic core radius to the electronic density radius). In the case of the light trivalents, an increase of $r_{c} / r_{s}$ favors a symetrical shape of $S(q)$. When undercooling, $r_{c} / r_{s}$ increases by $0.5 \%$ in Ga but $2 \%$ in $\mathrm{Al}$. In the latter metal this variation counter balances the influence of the Friedel oscillations. The hard-sphere like behaviour of $A 1$ at $0.5 \mathrm{~T}_{\mathrm{M}}$ is also confirmed in fig. $2 \mathrm{C}$. The theoretical $\mathrm{g}(\mathrm{r})$ is indeed very close to the pure hard sphere calculation of (1) by neglecting the influence of $V_{a}(r)$. The asymetrical second peak at $r=8 \mathrm{a} . \mathrm{u}$. is that of the HS one at high packing fraction $/ 13 /$, and is reminiscent of the random close packing of spheres.

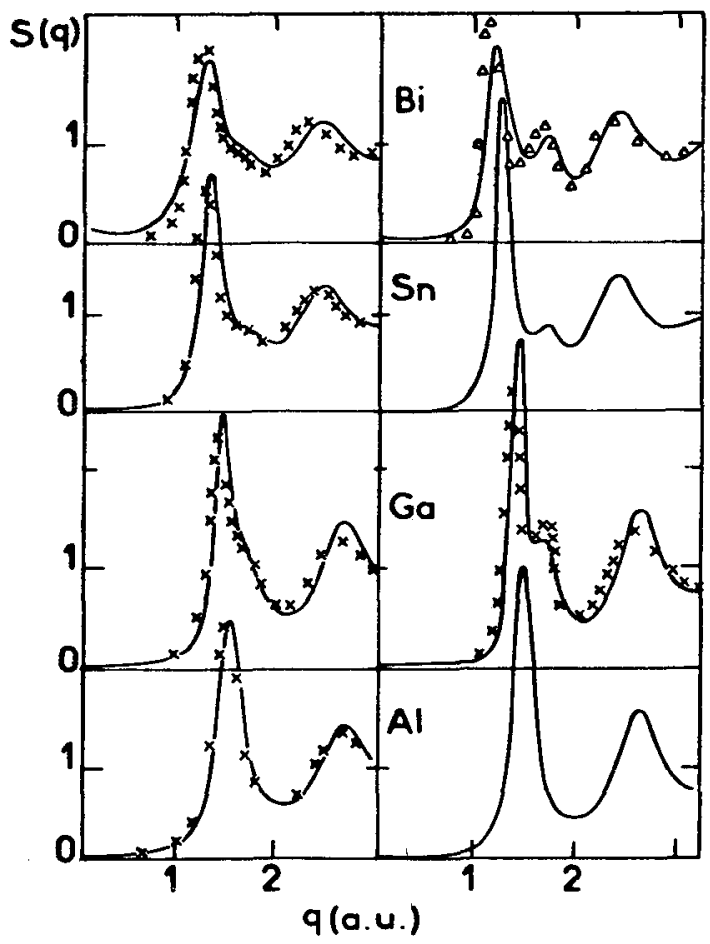

a b

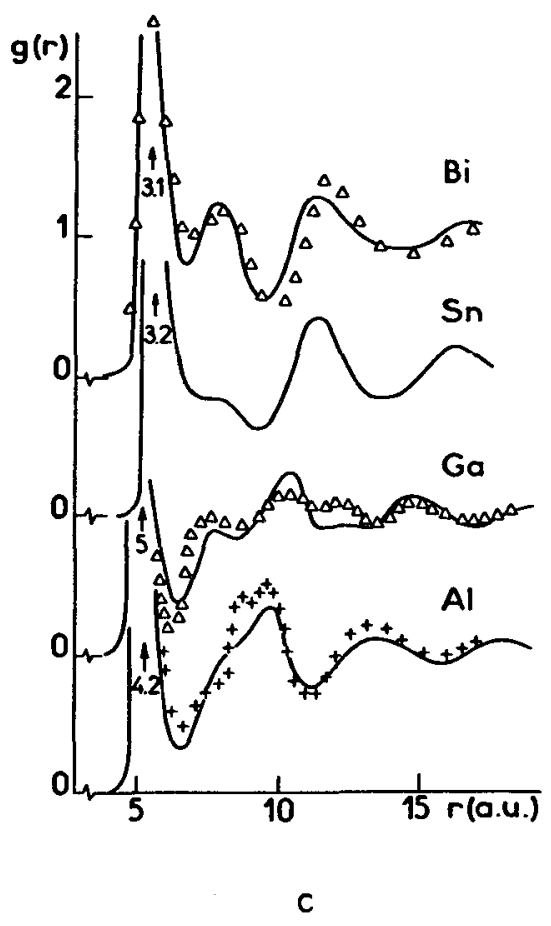

Fig.2 - Structure factors at $T_{M}(a), 0.5 T_{M}(b)$ and pair correlation functions at $0.5 \mathrm{~T}_{M}(\mathrm{c})$. Theory(full line). Experiments near $\mathrm{T}_{M} \mathrm{Bi}, \mathrm{Sn}$, Ga, Al /1,18/ (crosses $\mathrm{x}$ ).

Experiments near $0.5 \mathrm{~T}_{M}: \mathrm{Ga} / 1 /$ (crosses $\mathrm{x}$ ). Amorphous $\mathrm{Bi}$ and Ga at $4 \mathrm{~K} / 12 /$ (triangles) Simulation of a hard sphere glass /14/ (crosses +).

However, such an effect isless pronounced than in the Bernal model or in the simulation of the glassy state of the HS $/ 14 /$. For Al and Ga at $T=0.5 \mathrm{~T}_{M}$ we obtain for the underlying $H S n=0.54$ and $n=0.57$. It is also possible that in this range of $n$, the HS model that we use is less accurate (the Verlet-Weis model of HS is fitted to Monte Carlo results in an range $n<0.5$ ). Whatever it may be, our result exhibits the preferred arrangment of the hypothetical undercooled AT towards the random close packing. In the case of $\mathrm{Sn}$ and $\mathrm{B} i$ we equally obtain a specific evolution of the structure. Moreover we need not to speculate about the accuracy of the HS system since the packing fraction obtained are respectively 0.40 and 0.46 . One remarkable result is the strong analogy between undercooled $\mathrm{Bi}$ at $0.5 \mathrm{~T} \mathrm{M}$ and pure amorphous $\mathrm{Bi}$ at $4 \mathrm{~K}$ (fig. 2c).

Trends in $\mathrm{Cp}$

To obtain $C p$, we calculate the entropy $S(T, P)$ along the line of the constant normal pressure in the phase diagram. Then we calculate the mean derivative of $S V_{S}$ tempera- 
ture by large steps of $0.1 T_{M}$ to obtain stable results for $C p$. The values of $C p$, and of the entropy $S_{F}$ in excess from the ideal gas value are given in table 1 and fig.3 in units of the Boltzmann constant $k_{B}$.

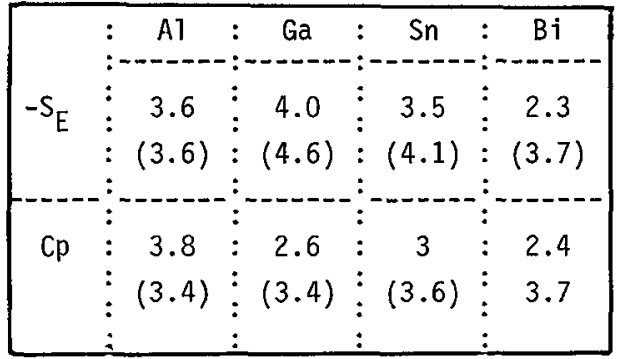

Table 1 : Calculated

Excess entropy and heat capacity at $T_{M}$ the experimental values are in parenthesis and from /15/

The results are very convenient decreases as we go toward the heavy polyvalents. Although the pair forces model is certainly incomplete to explain all the configurational change in the undercooled state, we see that the rise in $C p$ observed in $/ 2 /$ is approximatively reproduced (fig.3).

\section{Resistivities}

The resistivity $\rho$ and its derivative at the melting point are reported table 2. To point out the effect of the structural evolution when undercooling we also calculate the resistivity in the soft sphere approximation, where the effect of $V a(r)$ is neglected $/ 7 /$. We can observe in fig.4 that the change of $\partial p$ due to $\mathrm{Va}(r)$ increases from $\mathrm{Al}$ to $\mathrm{Bi}$ in different ways. In the range $0.5-1.5 \mathrm{~T}_{\mathrm{M}} \overrightarrow{\mathrm{\partial T}}$ the TDR is almost constant in $\mathrm{Al}$. In Ga we obtain a small maximum near $T_{M}$, in qualitative agreement with $/ 10 /$, but no such maximum appears in $\mathrm{Sn}$ as suggested in $/ 10 \%$. The main effect that we expect will be a rapid decrease of the TDR at deep level of undercooling due to the progressive departure from the HS-like structure.

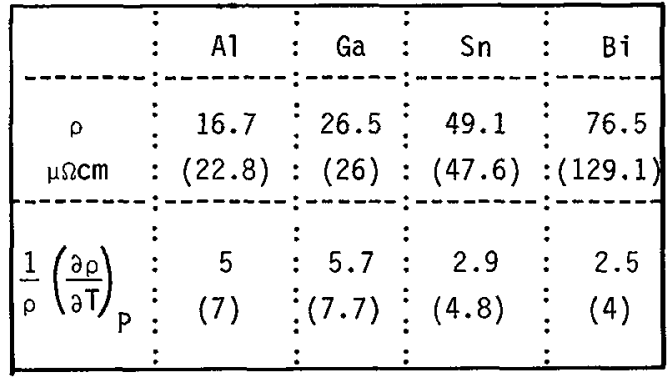

Table 2 : Resistivity and temperature coefficient for $T=T_{M}$. The experimental values are in parenthesis and from $/ 10,17 /$.

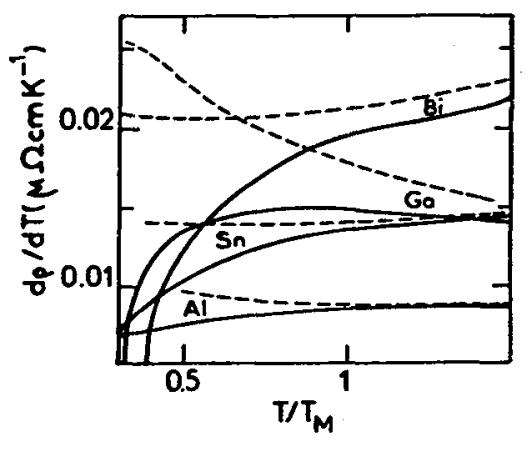

Fig.4 - TDR theory (fult line) The dashed line corresponds to the soft sphere modeT. 


\section{REFERENCES}

/1/ BIZID A., BOSIO L., CURIEN H., DEFRAIN A. and DUPONT M., Phys. Status Solidi, a23 (1974) 195.

12/ PEREPEZKO J.H. and PAIK J.S., J. Non Cryst. Solids, 61 (1984) 113.

13/ ANDERSEN H.C., ChANDLER D. and WEeKS J.D., J. Chem. Phys., 56 (1972) 3812 , and J. Physique Co11., 41 C8 (1980) 603.

14/ REGNAUT C., BADIALI J.P. and DUPONT M., Phys. Lett., 74A (1979) 245. (erratum Phys. Lett., $75 A$ 516) and J. Physique Col7. 41 C8 (1980) 603.

/5/ HAFNER J. and KAHL G., J. Phys. F Met. Phys., 14 (1984) 2259. See also HAFNER J. J. Non-Cryst. Solids, 61 (1984) 175.

/6/ BRETONNET J.L. and REGNAUT C., Phys. Rev., B15, 31 (1985) 5071.

17/ Regnaut C. and BRetONnet J.L., J. Phys. F Met. Phys., 14 (1984) L85.

18/ SINGH H.B. and HOLZ A., So1. Stat. Comm., 45 (1983) 985.

19/ SJÖLANDER A. and TURSKI L.A., J. Phys. C Solid. State Phys., 11 (1978) 1973.

/10/ POKORNY M. and ASTRÖM H.U., J. Phys. F Met. Phys., 6 (1976) 559.

/11/ CRAWLEY A.F., Int. Met. Rev., 19 (1974) 32.

/12/ BERERHI A., BIZID A., BOSIO L., CORTES R., DEFRAIN A. and SEGAUD C., J. Physique Co11., 41 C8 (1980) 218.

and BERERHI A., Thēse d'Etat Paris 1981.

/13/ WEEKS J.D., Phil. Mag., 35 (1977) 1345.

/14/ WOODCOCK L.V., Annals of the N.Y. Academy of Science, Ed. by J.M. O'Reilly and M. Golstein (1981).

/15/ SHIMOJI M., Liquids Metals (1977) (New York Acad. Press).

/16/ BOSIO L., CORTES R., DEFRAIN A. and FOLCHER G., J. Chim. Phys., 2 (1973) 357.

/17/ GASSER G.J., Thèse d'Etat, Université de Metz (1982).

/18/ WASEDA Y., The structure of non-crystalline materials : liquid and amorphous solids Mc Graw HiTl N.Y. (1980). 